\title{
BUAH TOMAT (Solanum Iycopersicum) SEBAGAI BAHAN PEMUTIH GIGI ALAMI
}

\author{
Nurwiyana Abdullah, Munadirah
}

\begin{abstract}
ABSTRAK
Studi ini mengenai efek buah tomat (Solanum lycopersicum) sebagai bahan pemutih gigi alami. Penampilan merupakan salah satu aspek yang sangat diperhatikan seseorang dalam melakukan interaksi sosial pada zaman modern sekarang ini. Proses pemutihan gigi dapat dilakukan dengan menggunakan bahan kimiawi atau bahan alami, tetapi bahan kimiawi tidak jarang menimbulkan efek samping pada gigi seperti nyeri pada gigi, kerusakan pada daerah pulpa, kerusakan pada jaringan keras gigi dan kerusakan pada mukosa. Ekstrak buah tomat mengandung hidrogen peroksida yang dapat memutihkan gigi dan sudah terbukti memiliki khasiat memutihkan gigi. Tujuan penelitian ini untuk mengetahui efektifitas buah tomat sebagai bahan pemutihan gigi Alami. Jenis penelitian yang digunakan dalam penelitian ini adalah studi literatur dimana data yang digunakan adalah data sekunder yang bersumber dari jurnal maupun referensi-referensi yang ada.
\end{abstract}

Kata Kunci: Alami, Pemutih Gigi, Tomat.

\section{PENDAHULUAN}

Penampilan merupakan salah satu aspek yang sangat diperhatikan seseorang dalam melakukan interaksi sosial pada zaman moderen sekarang ini. Gigi yang putih merupakan salah satu hal yang diinginkan masyarakat untuk menunjang penampilan mereka sehingga dapat memeiliki kepercayaan diri yang tinggi ketika mereka bertinteraksi.

Perubahan warna pada gigi dapat di sebabkan oleh faktor eksternal(luar),internal(dalam) atau keduaduanya (Gursoy dkk, 2008) membuat banyak orang merasa tidak nyaman ketika berbicara atau tersenyum,karena mereka berkeyakinan bahwa gigi mampu membuat orang merasa lebih cantik dan percaya diri (Vanabel dan LoPresti, 2004).

Pewarnaan pada gigi merupakan problem estetika yang dapat mempengaruhi psikologi seseorang. Warna gigi yang berubah dapat mengurangi keindahan penampilan dan mengurangi rasa percaya diri. Oleh sebab itu senyum yang cerah dengan gigi yang putih menjadi dambaan setiap orang. Hal ini menyebabkan meningkatnya kebutuhan pelayanan gigi estetik,terutama pemutihan gigi (Joiner, 2006).

Pada dasarnya proses penghilangan warna gigi dilakukan dengan whitening yang berarti penghilangan warna agar warna gigi kembali ke warna asal atau bleaching yang berarti pemutihan gigi. Oleh karenanya,terdapat dua macam bahan untuk memutihkan gigi,yaitu menggunakan produk bleaching atau produk whitening (nonbleaching). Bahan bleaching membantu menghilangkan pewarnaan yang bermula dari dalam gigi (instrinsik) dan juga pewarnaan di permukaan gigi (ekstrinsik) yang hasilnya dapat mengubah warna asli gigi. Produk whitening (pemutih) hanya untuk menghilangkan pewarnaan di permukaan gigi saja,mengandung bahan yang bekerja menghilangkan pewarnaan di permukaan gigi saja,mengandung bahan yang bekerja menghilangkan pewarnaan dengan aksi fisik dan kimia (Bernie,2003; Irmawati, 2004 Silva dkk, 2005).

\section{METODE PENELITIAN}

Jenis penelitian yang digunakan dalam penelitian ini adalah studi literatur. 
Dimana studi literatur adalah salah satu teknik untuk mencari referensi teori yang relevan dengan kasus terhadap permasalahan yang ditemukan. Adapun tujuan dari penelitian ini adalah untuk mengetahui efektifitas buah tomat sebagai bahan pemutih gigi alami.

\section{PEMBAHASAN}

Pemutihan gigi adalah prosedur untuk mencemerlangkan gigi dan menghilangkan pewarnaan gigi. Pewarnaan gigi adalah suatu perubahan warna pada gigi yang disebabkan oleh faktor eksternal (luar), internal (dalam) atau kedua-duanya. Pewarnaan pada gigi dapat digolongkan menjadi pewarnaan eksterinsik dan pewarnaan intrinsik. Pewarnaan eksterinsik adalah pewarnaan superfisial dan memengaruhi hanya permukaan luar email. Proses terjadinya pewarnaan gigi karena kromogen makanan/minuman (kopi, teh, wine). Sedangkan pewarnaan intrinsik diakibatkan oleh persatuan dari material kromogenik di dalam email dan dentin, seperti pemakaian antibiotik, misalnya tetrasiklin

Perubahan warna gigi atau diskolorisasi gigi dapat ditanggulangi dengan dua cara yaitu menggunakan bahan kimia dan bahan alami. Bahan kimia digunakan oleh dokter bleaching. Dental bleaching merupakan suatu cara memutihkan kembali gigi yang berubah warna menjadi lebih putih dengan proses perbaikan secara kimiawi.

Indonesia kaya akan keanekaragaman hayati yang memiliki potensi untuk dikembangkan salah satunya adalah buah tomat (Solanum lycopersicum) sangat mudah dijumpai dan sering dimanfaatkan sebagai pelengkap masakan.
Senyawa hydrogen peroksida yang terkandung didalam tomat memilki efek memutihkan gigi. Buah tomat memiliki kandungan hydrogen peroksida yang dapat memutihkan gigi dan sudah terbukti khasiat dalam memutihkan gigi, kandungan tomat juga dapat meningkatkan kecepatan hydrogen peroksida dalam mereduksi warna. Sehingga kandungan hydrogen peroksida dan peroksidase pada tomat dapat digunakan sebagai bahan alternatif untuk memutihkan gigi.

Berdasarkan penelitian Tin O (2011) di Hospital University Sains Malaysia dinyatakan bahwa 124 dari 235 pasien (52,8\%) yang terdiri dari 70 pria dan 165 wanita mereka menyatakan bahwa tidak puas dengan penampilan gigi mereka. Hal yang paling dikeluhkan yakni pemutihan gigi (teeth whitening) adalah perlakuan yang paling diharapkan oleh kebanyakan pasien.

Menurut pendapat Goldstein (1999) dan Greenwall (2001) dalam joiner (2006) mengatakan bahwa untuk pemutihan gigi di klinik biasanya digunakan 25-35\% hydrogen peroksida, selanjutnya diaktifkan dengan panas atau sinar dan hasilnya dapat dilihat setelah satu kali kunjungan (periode waktu yang pendek). Suprastiwi (2005) juga menjelaskan bahwa konsentrasi peroksida yang tinggi mempunyai kecepatan sedikit lebih cepat dalam memutihkan gigi, mendapatkan hasil yang cepat, akan tetapi akan cepat juga menjadi relaps dan butuh waktu yang panjang untuk menjadi stabil, serta kemungkinan kejadian sensitivitas pada gigi juga lebih tinggi.

Berbeda dengan penelitian Saputro dan Wibowo (2009) menujukkan bahwa jus tomat atau buah tomat mampu memutihkan gigi pada gigi post ekstraksi karena dalam 1 
buah jus tomat terdapat kandungan hidrogen peroksida sebesar $4000 \times 10-9$ mol. Pada ekstrak buah tomat juga terdapat peroksida dalam mereduksi warna.

Sedangkan pada penelitian yang dilakukan oleh Hilma 2017 yang menguji efek lain dari kandungan buah tomat yakni asam askorbat dengan berbagai konsentrasi yakni pada konsentrasi 30\%, 70\%, dan $100 \%$ didapatkan hasil ekstrak tomat dengan berbagai konsentrasi efektif dalam pemutihan gigi.

Merupakan zat yang secara efektif mengandung superoksida, hidrogen peroksida, singlet oksigen dan radikal bebas lainnya. Kandungan hidrogen peroksida mampu merusak molekul-molekul zat warna sehingga mampu memberikan efek pemutih pada gigi. Sehingga kandungan hidrogen peroksida dan peroksidase pada tomat dapat digunakan sebagai bahan alternative untuk memutihkan gigi. Hal ini sejalan dengan penelitian Mardhiyah (2012) yang melaporkan bahwa perendaman gigi dalam ekstrak tomat $100 \%$ selama 3 harilebih efektif dan sudah cukup maksimal untuk dapat memberikan efek pemutihan pada gigi secara in vitro.

\section{KESIMPULAN}

Salah satu terapi alternatif pemutihan pada gigi adalah dengan ekstrak buah tomat. Buah tomat memiliki kandungan hidrogen peroksida yang setara dengan melakukan pemutihan gigi dengan menggunakan senyawa kimia yang sering digunakan. Berbagai macam kandungan dari senyawa lainnya pada buah tomat dapat memberikan efek teet whitening secara alami.

\section{SARAN}

Diharapkan kepada masyarakat agar dapat mengaplikasikan buah tomat sebagai bahan pemutih alami gigi.

\section{DAFTAR PUSTAKA}

Vanable, E. dan LoPresti, L. R. 2004. Using Dental Material. Person Prenti ce Hall, New Jersey, 80-85.

Joiner, A. 2006. The Bleaching of Teeth: A Review of The Literature. J. Dent., $34,412-419$.

Bernie, k. M. 2003. Maintaining Toothwhitening Results. J. Pract Hygiene, 34-36.

Ross Kerr, Jonathan A Ship. 2007. Tooth Discoloration. eMedicine Article last update: mar 16.

Surtinah. 2007. Kajian Tentang hubungan Pertumbuhan Vegetatif Denga Produksi Tanaman tomat (lyopersicion esculentum, Mill) Ps, Agronomi, staf pengajar fakultas Pertanian Universitas Lancang Kuning, vol. 4 No 1.

Rismanto D. Y. Damayant I. M, Dharmo, R. H. 2005. Dental Whitening. PT Dental Limas Media Utama, Jakarta, 9 - 14.

Rasinta dkk. 2012. Perawatan Pulpa Gigi (Endodonti), Buku kedokteran EGC, Jakarta.

Taringan Rasinta dkk. 2013. Perawatan Pulpa Gigi (Endodonti) Edisi 3, Buku Kedokteran EGC, Jakarta.

Haywood, V. B. 2006. Nightguard Vital Bleaching Indication and Limitation. $S$, us Dentistry, Section Heading Sub Heading, 2 - 8.

Swift, E. J. 1988. A Meethod For Bleaching Discolored vital Teeth. J. Quintessence Int., 19 (9): 607 611.

Yunita, 2013. Serba - serbi Ilmu Konservasi Gigi, Universitas Indonesia: Jakarta.

Taringan, 2012. Perawatan Pulpa Gigi (Endodontik), Edisi 2. EGC: Jakarta.

Rinaldi, 2019. Budidaya tomat, Garuda Pustaka; Jakarta Timur.

Supriati, Y. 2009. Bertanam Tomat dalam Pot dan Polibag, cetakan 1. Penebar Swadya; Jakarta.

Tisnawati, Y. Setiawan, A. I, 1995. Membudidayakan secara komersial. Jakarta: Penebar Swadya.

Mulky, I, H. Rani, N. Kusuma, N. Tsabitha, S, f. 2014 The Influence of Tomato Juice As An Alternatif treatment To whiten The Teeth. Indonesia 
Scholars Journal Vo; No. 45. Andalas University.

Pratiwi, Septiv Asih. 2009. Pengaruh pemberian jus tomat terhadap Perubahan warna gigi pada proses pemutihan Gigi secara in Vitro (skripsi). Semarang: Fakultas Kedokteran, Univeritas Diponegoro

Suprastiwi E. penggunaan karbamid Peroksida sebagai Bahan Pemutih gigi. Ind J Dentistry (Internet). 2005 (Distribusi Tanggal 14 Desember 2018); 12 (3): 139 - 145.

Hilma FM. Dwi WKA, Zita A. 2017. Efektifitas Asam Askorbat dalam Ekstrak buah tomat (Esculentum) terhadap konsentrasi $30 \%, 70 \%$ dan $100 \%$. Semarang: Universitas 